\title{
Arctic regional methane fluxes by ecotope as derived using eddy covariance from a low-flying aircraft
}

\author{
David S. Sayres ${ }^{1}$, Ronald Dobosy ${ }^{2,3}$, Claire Healy ${ }^{4}$, Edward Dumas ${ }^{2,3}$, John Kochendorfer ${ }^{2}$, Jason Munster ${ }^{1}$, \\ Jordan Wilkerson ${ }^{5}$, Bruce Baker ${ }^{2}$, and James G. Anderson ${ }^{1,4,5}$ \\ ${ }^{1}$ Paulson School of Engineering and Applied Sciences, Harvard University, 12 Oxford Street, Cambridge, MA 02138, USA \\ ${ }^{2}$ Atmospheric Turbulence and Diffusion Division, NOAA/ARL, Oak Ridge, TN 37830, USA \\ ${ }^{3}$ Oak Ridge Associated Universities (ORAU), Oak Ridge, TN 37830, USA \\ ${ }^{4}$ Department of Earth and Planetary Sciences, Harvard University, 12 Oxford Street, Cambridge, MA 02138, USA \\ ${ }^{5}$ Department of Chemistry and Chemical Biology, Harvard University, 12 Oxford Street, Cambridge, MA 02138, USA \\ Correspondence to: David Sayres (sayres@ huarp.harvard.edu)
}

Received: 27 September 2016 - Discussion started: 30 September 2016

Revised: 19 May 2017 - Accepted: 7 June 2017 - Published: 14 July 2017

\begin{abstract}
The Arctic terrestrial and sub-sea permafrost region contains approximately $30 \%$ of the global carbon stock, and therefore understanding Arctic methane emissions and how they might change with a changing climate is important for quantifying the global methane budget and understanding its growth in the atmosphere. Here we present measurements from a new in situ flux observation system designed for use on a small, low-flying aircraft that was deployed over the North Slope of Alaska during August 2013. The system combines a small methane instrument based on integrated cavity output spectroscopy (ICOS) with an air turbulence probe to calculate methane fluxes based on eddy covariance. We group surface fluxes by land class using a map based on LandSat Thematic Mapper (TM) data with $30 \mathrm{~m}$ resolution. We find that wet sedge areas dominate the methane fluxes with a mean flux of $2.1 \mu \mathrm{g} \mathrm{m}^{-2} \mathrm{~s}^{-1}$ during the first part of August. Methane emissions from the Sagavanirktok River have the second highest at almost $1 \mu \mathrm{g} \mathrm{m}^{-2} \mathrm{~s}^{-1}$. During the second half of August, after soil temperatures had cooled by $7^{\circ} \mathrm{C}$, methane emissions fell to between 0 and $0.5 \mu \mathrm{g} \mathrm{m}^{-2} \mathrm{~s}^{-1}$ for all areas measured. We compare the aircraft measurements with an eddy covariance flux tower located in a wet sedge area and show that the two measurements agree quantitatively when the footprints of both overlap. However, fluxes from sedge vary at times by a factor of 2 or more even within a few kilometers of the tower demonstrating the importance of making regional measurements to map out methane emissions spatial heterogeneity. Aircraft
\end{abstract}

measurements of surface flux can play an important role in bridging the gap between ground-based measurements and regional measurements from remote sensing instruments and models.

\section{Introduction}

Methane is the third most important greenhouse gas after water vapor and carbon dioxide, and its concentration in the atmosphere has increased from a pre-industrial value of 0.7 parts per million by volume (ppmv) to its current value of approximately $1.85 \mathrm{ppmv}$. Methane sources are varied, with major contributors being anthropogenic (including fossil and agricultural) as well as natural. Often multiple sources occur in the same vicinity, for example emissions from gas wells collocated with agricultural fields or with pasture for grazing livestock.

In the past few years there have been increased efforts to understand how methane emissions, as well as carbon dioxide, might change from the Arctic region in response to warmer temperatures (Yvon-Durocher et al., 2014; Sturtevant et al., 2012; Sturtevant and Oechel, 2013; Walter et al., $2007 \mathrm{~b}$, and references therein). For example, temperatures in the Alaskan North Slope have increased $0.6{ }^{\circ} \mathrm{C}$ per decade for the last 30 years. Likewise, in that same time period the minimum extent of Arctic sea ice at the end of the summer has decreased from 8 to 5 million $\mathrm{km}^{2}$. Until this past century late- 
summer sea ice extent was 10 million \pm 1 million $\mathrm{km}^{2}$ over the past 1500 years (Kinnard et al., 2011). Global methane concentrations have also varied during this time period, with atmospheric increases slowing down in the 1990s, leveling off in the early part of the 21st century and have been increasing again since 2007 with concentrations reaching $1.8 \mathrm{ppmv}$ in 2010 based on several surface-based observation networks (Kirschke et al., 2013). It has been postulated that the increase could be from Arctic wetlands (Koven et al., 2011; Walter et al., 2007b).

A brief look at the carbon stock in the Arctic reveals why it has garnered so much attention. The Arctic permafrost region contains between 1330 and $1580 \mathrm{Pg}$ of carbon in the tundra surface layer (0-3 m depth), yedoma deposits, and rivers. An additional quantity is contained in deeper deposits and sub-sea permafrost (Tarnocai et al., 2009). Arctic carbon stock represents about a third of the total global surface carbon pool and increases to $50 \%$ when accounting for the deeper soils (Schuur et al., 2015). As the climate continues to warm, this carbon is vulnerable to thaw and decomposition by microbes, potentially leading to large increases in methane and carbon dioxide emissions. Methane from anaerobic reduction of organic carbon stocks in permafrost is particularly important, having a warming potential more than twenty times that of carbon dioxide on a 100 -year timescale and greater yet over shorter time periods (Boucher et al., 2009). The correlation between a warming Arctic and the release of methane and carbon dioxide from northern wetlands and ocean clathrates is strongly evident in the paleoclimate record (Zachos et al., 2008; Whiticar and Schaefer, 2007). This relationship is also seen (1) in current observations of methane release from thermokarst lakes formed from melting Arctic permafrost each spring and summer (SepulvedaJauregui et al., 2015; Walter et al., 2007b; Bastviken et al., 2004; Casper et al., 2000), (2) in ebullition from deep sea sediments (Shakhova et al., 2014; Reagan et al., 2011; Damm et al., 2010), and (3) from airborne campaigns (Wofsy, 2011; Chang et al., 2014).

The North Slope of Alaska is covered by several different land classes though dominated by permafrost. Access to the interior normally requires aircraft, except along the Dalton Highway (Rt. 11) from Fairbanks to Prudhoe Bay. The lack of infrastructure, especially roads, makes continuous ground-based measurements difficult except near major settlements. This sparsity of data increases the uncertainty in regional bottom-up estimates of carbon flux. At the same time top-down estimates based on inversion modeling from measured concentration profiles rely on knowledge of flux sources on the ground to determine which sources are dominating the emissions in areas like the North Slope, with its multitude of broad-scale emitters and point sources. A scale gap exists between process-level studies on the ground and large-scale regional estimates from remotely sensed data or inversion-model results. Airborne measurements, especially from low-flying aircraft, have the potential to bridge this gap. Flux measurements from low-flying aircraft coordinated with surface measurements promote extension of the detailed surface-flux measurements to the larger regional scale by mapping the heterogeneity in the fluxes over these larger areas.

Eddy covariance is a direct way to determine in situ the exchange (flux) of mass, momentum, and energy between the atmosphere and the surface. Turbulent winds and concentrations are measured at a high sample rate, and their covariance yields the flux. With stationary instruments the wind and concentration measurements can be routinely obtained, and eddy covariance from fixed sites is widely represented in the literature as a way of obtaining the flux of a quantity between the surface and atmosphere. Obtaining eddy covariance measurements from a moving aircraft presents some unique challenges including accurately measuring turbulent wind velocity relative to the ground and measuring concentrations at a sufficiently high data rate. Furthermore, if the flux from the aircraft is to be a good proxy for a measurement taken at the surface, it needs to be sampled close to the ground. The appropriate distance varies depending on boundary layer height, turbulence, and the footprint size of interest. Several groups have successfully measured carbon dioxide and heat flux from low-flying aircraft in the Arctic (Zulueta et al., 2011; Oechel et al., 2000, 1998; Gioli et al., 2004), Europe (Bange et al., 2007; Vellinga et al., 2010; Hutjes et al., 2010; Gioli et al., 2006), Asia (Metzger et al., 2013), and continental USA (Kirby et al., 2008; LeMone et al., 2003; Avissar et al., 2009).

Here we present methane fluxes taken during the summer of 2013 in the North Slope of Alaska and use the data to explore several questions. For example, how representative are towers' footprints of other instances of the remotely determined land-cover class in which they were placed? In principle a stationary site can measure all manner of properties and state variables in the soil, the vegetation, and the air, within and above the canopy. Much can be learned about the bacteria, soil chemistry, canopy storage, and other quantities relevant to the exchange of mass, momentum, and energy with the surface. But all of this is known only at a particular site. How representative is that site of other locations that to remote sensors appear similar? Are there land-cover classes that are particularly indicative of emissions of a given trace gas? Can the land class so identified be used as a quantitative predictor of a particular type of soil chemistry? This is relevant in assessing the regional methane emissions from remote sensing. Methane in particular has a fairly complex chemistry in the soil involving state quantities such as the (sub-canopy) soil temperature and the height of the water table. These are measurable only in situ, so that having a proxy indicator such as vegetation cover would be valuable. Interval quantities ${ }^{1}$ sensible remotely, such as normalized

\footnotetext{
${ }^{1}$ An interval quantity such as temperature can take an ordered range of values the length of which has meaning, as opposed to a
} 


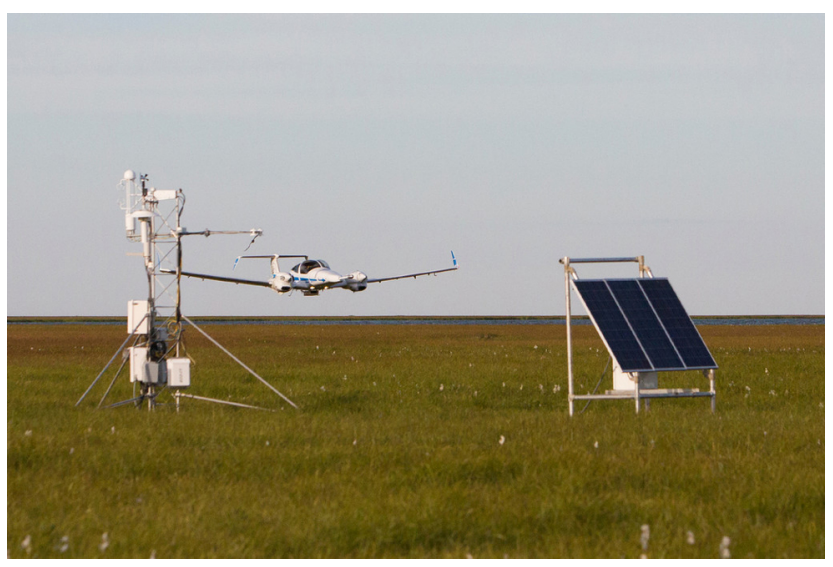

Figure 1. Picture of the FOCAL system flying near the NOAA/ATDD flux tower in North Slope, AK.

difference vegetation index (NDVI), air temperature, and other vegetative indexes that correlate with carbon dioxide do not correlate with methane (Olefeldt et al., 2013). Vegetation classifications determined remotely, however, have been shown in other regions to be useful for estimating regional methane emissions (e.g., Schneider et al., 2009) in upscaling from ground measurements.

Aircraft, though more limited in what they can measure than fixed sites, are very mobile providing the opportunity to sample many instances of the same remotely sensed class over the landscape. From this multi-instance sample one can assess how representative the single fixed site is. One can also assess the strength of the variability within the given land surface class for later investigation from the surface. In remote parts of the earth, in particular, if surfaces of recognizably similar character (class) can be shown to have comparable emissions properties, considerable effort can be saved over a surface-based survey. Alternatively, large variation within a class that is not currently well predicted by some remotely measurable interval quantity will be seen as requiring additional effort for in situ measurements to find an effective monitoring program for methane emissions from that surface class.

\section{Methods}

To measure methane emissions over large areas of the North Slope, the Flux Observations of Carbon from an Airborne Laboratory (FOCAL) system was flown during August 2013 out of Deadhorse Airport, Prudhoe Bay, AK. FOCAL, pictured in Fig. 1 flying near the NOAA Atmospheric Turbulence and Diffusion Division (NOAA/ATDD) flux tower, consisted of three main parts: the aircraft, a Diamond DA42 from Aurora Flight Sciences; a turbulence probe, the

set of categories such as surface classes having no notion of order or length.
Best Airborne Turbulence (BAT) Probe from NOAA/ATDD; and a fast methane and water instrument from the Anderson Group at Harvard University. Data presented in the results section were obtained during six flights between 13 and 28 August (Fig. 2 and Table 1, Sayres and Dobosy, 2013). During three of these flights the aircraft made repeated passes near the NOAA/ATDD tower that was set up for comparisons. The other three flights were flown as grid patterns over large regional areas $(\sim 50 \mathrm{~km} \times 50 \mathrm{~km})$ to better sample the heterogeneity of different land types over a large region. These flights consisted both of profiles from the bottom of the boundary layer $(\sim 5-10 \mathrm{~m})$ up to $\sim 1500 \mathrm{~m}$ altitude and also long transects $(\sim 50 \mathrm{~km})$ at low altitudes $(<25 \mathrm{~m})$ that are used to access surface flux using eddy covariance.

\subsection{FOCAL instrumentation}

Fluxes of trace gases are covariances between turbulent winds and fluctuations in gas concentrations. The airborne methane flux calculations rely on having fast measurements of both turbulent wind velocity and dry-air mixing ratio, with the two quantities being coordinated in time and space to within an error much smaller than the measurement interval.

To measure turbulent wind, temperature, and pressure NOAA/ATDD developed the Best Aircraft Turbulence (BAT) probe in the 1990s as a pioneering low-cost solution for mobile atmospheric turbulence measurements (Crawford et al., 1996, 1993; Crawford and Dobosy, 1992). The BAT probe consists of a hemisphere, $15.5 \mathrm{~cm}$ in diameter, with nine pressure ports located at selected positions on the probe head. The vertical and horizontal pairs of ports measure the differential pressure between them to calculate the angle of attack and side slip, respectively. Static pressure is taken from the average of the pressures measured at the four diagonal pressure ports corrected for non-zero attack and sideslip angles. Dynamic pressure is measured from the difference between the pressure measured at the center hole and the static pressure, again adjusted for non-zero values of the angles of attack and sideslip. These pressure measurements are combined with a known model for flow over a hemisphere to determine 3-D wind direction and speed relative to the probe. The velocity of the probe relative to the ground is measured by three interconnected instrument systems: a GPS/INS system located near the center of gravity (CG) of the aircraft, accelerometers located in the probe, and two additional GPS antennas, one on the BAT probe and the other atop the main cabin (Crawford and Dobosy, 1997, 1992). The BAT probe digitizes samples at $1600 \mathrm{~s}^{-1}$, applies a low-pass filter to suppress aliasing, and subsamples at $50 \mathrm{~s}^{-1}$. The wind measurements are synchronized with the $50 \mathrm{~s}^{-1}$ signal from the GPS/INS system.

Before the FOCAL system was assembled, the BAT probe was characterized in a wind tunnel (Dobosy et al., 2013). A similar BAT probe was also tested in flight on a different aircraft (Vellinga et al., 2013, hereafter V2013). After 


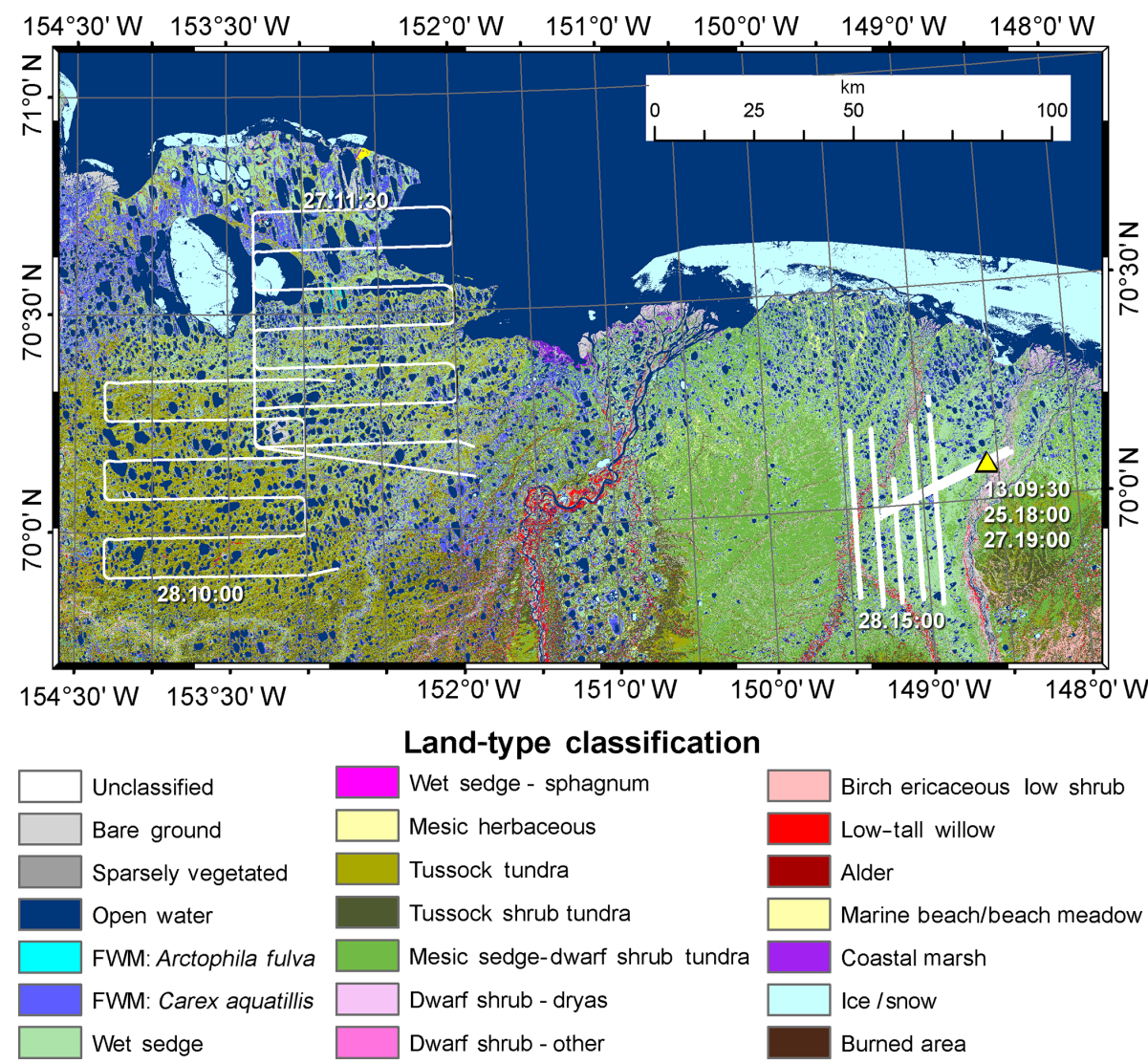

Figure 2. Six flight tracks flown by FOCAL during August 2013 are shown in white. Flights are given in the figure as DD.HH:MM, where DD is the date in August and HH:MM is the time (UTC -10) of the middle of the flight rounded to the nearest half-hour. Flight tracks are shown only for the portions flown within $25 \mathrm{~m}$ of the ground. The underlying chart gives the NSSI-assigned land-cover class produced from LandSat $30 \mathrm{~m}$ Thematic Mapper data. The yellow triangle locates the NOAA/ATDD flux tower.

Table 1. Flights used in the analysis along with location, time of day, mean air temperature, and surface land classes.

\begin{tabular}{llrrrl}
\hline $\begin{array}{l}\text { Flight date } \\
\text { DD.HH:MM }\end{array}$ & Location & $\begin{array}{r}\text { Start time } \\
\text { UTC }-10\end{array}$ & $\begin{array}{r}\text { End time } \\
\text { UTC }-10\end{array}$ & $\begin{array}{r}\text { Temperature }^{2} \\
\left({ }^{\circ} \mathrm{C}\right)\end{array}$ & \begin{tabular}{l} 
Dominant land classes $^{3}$ \\
\hline 13.09:30
\end{tabular} Tower \\
25.18:00 & Tower & $08: 19$ & $10: 22$ & 16 & Sedge, Mesic sedge, Lakes, Sag River, FWM \\
$27.11: 30$ & Western grid & $09: 40$ & $19: 49$ & 5 & Sedge, Mesic sedge, Lakes, Sag River, FWM \\
$27.19: 00$ & Tower & $16: 46$ & $20: 02$ & 6 & Sedge, FWM, Lakes, Tussock tundra \\
$28.10: 00$ & Western grid & $08: 39$ & $11: 39$ & 10 & Sedge, Mesic sedge, Lakes, Sag River, FWM \\
$28.15: 00$ & Eastern grid & $13: 59$ & $15: 44$ & 11 & Tussock tundra, Lakes, FWM, and Sedge \\
& & 16 & Sedge, Mesic sedge, Lakes, Kuparuk River, FWM \\
\hline
\end{tabular}

${ }^{1}$ All flights are during August 2013. DD is the local date of the flight and HH:MM is the middle time of the flight rounded to the nearest half-hour. ${ }^{2}$ Temperature calculated as mean temperature recorded by instrument during flight time and below $100 \mathrm{~m} .{ }^{3}$ Land classes are given in order of largest percent coverage first.

the FOCAL system was assembled, similar calibration maneuvers were flown in preparation for and during the Alaska campaign. As part of a calibration flight on the evening of 27 August in Alaska, we performed the yaw maneuver described by V2013 and obtained a residual contamination less than $10 \%$, as described there. A pitch maneuver described by V2013 was performed resulting in contamination of $10 \%$ for the high-frequency pitching (1.6 s period), which was the best executed of the pitch test's three parts and is the severest test.

The methane instrument draws air from an inlet located $8 \mathrm{~cm}$ aft of the BAT probe turbulence measurements. Flow of air through the axis is controlled by a dry scroll pump located in the back of the aircraft. Air from the inlet passes through $1.25 \mathrm{~cm}$ diameter tubes into the nose and forward luggage bay sections of the aircraft. The pressure of the air 
is controlled by a proportional solenoid valve and a pressure control board that uses pressure measured at the detection axis to feed back on the valve orifice position. The actual detection axis is located in the port-side forward luggage bay. The methane instrument uses integrated cavity output spectroscopy (ICOS) to measure $\mathrm{CH}_{4}, \mathrm{H}_{2} \mathrm{O}$, and $\mathrm{N}_{2} \mathrm{O}$ (Witinski et al., 2011). The ICOS instrument uses a highfinesse optical cavity composed of two high-reflectivity mirrors $(R=0.9996)$ to trap laser light for a period on the order of $2 \mu$ s producing effective path lengths of $10^{3}$ times the mirror separation. For the fast methane sensor used in this deployment, a small ICOS cell $(25 \mathrm{~cm}$ in length; mirrors $5 \mathrm{~cm}$ in diameter) was built that combines the sensitivity and stability of ICOS with a small sample volume to attain high flush rates $\left(17 \mathrm{~s}^{-1}\right)$, permitting a sample rate of $10 \mathrm{~s}^{-1}$. Using the wavelength region around $1292 \mathrm{~cm}^{-1}(7.74 \mu \mathrm{m})$, measurements of methane achieved a precision of $7 \mathrm{ppbv}(1 \sigma, 1 \mathrm{~s})$. Due to the high variability of water in the troposphere, water vapor measurements are required with any trace gas measurements in order to quantify dilution effects caused by changes in water vapor content as well as changes to spectroscopic line broadening (Webb et al., 1980; Gu et al., 2012). Well-defined absorption features of water vapor and its isotopologues as well as nitrous oxide are obtained in the same sweep of the laser, therefore the same instrument provides simultaneous measurements of nitrous oxide and water vapor along with methane. This technique provides an extremely high signalto-noise ratio as well as robust measurement in flight and has been the basis for several ICOS flight instruments built by this group (Witinski et al., 2011; Sayres et al., 2009; Engel et al., 2006; Paul et al., 2001). Periodic calibration in flight using calibrated gas cylinders tracks the drift over the course of the flight and from flight to flight.

To match the vertical wind's sample rate, gas series are interpolated to $50 \mathrm{~s}^{-1}$ using cubic splines. On some of the flights a buffer overflow problem (since corrected) caused sample loss leaving an irregular time series of samples between 3 and $4 \mathrm{~s}^{-1}$. The irregularity was readily handled by the interpolation to produce a signal, implicitly low-pass filtered with a stop band above about $1.5 \mathrm{~Hz}$, down from the full $5 \mathrm{~Hz}\left(10 \mathrm{~s}^{-1}\right)$. Plots of spectra and cospectra of the data streams of the vertical wind and of the trace gases' dry-air mixing ratios were prepared and are presented by Dobosy et al. (2017). To assess the potential loss of flux due to the lost samples, the full $10 \mathrm{~s}^{-1}$ gas data stream available from flight 25.18:00 was subsampled in two modes. One subsample was evenly spaced at $3 \mathrm{~s}^{-1}$; the other more randomly spaced between 3 and $4 \mathrm{~s}^{-1}$, representing flight 13.09:30. These were interpolated by cubic spline, which does not appreciably add higher-frequency components to the gas data streams above the (effective) Nyquist frequency of the original signal $(5 \mathrm{~Hz}$ for 25.18:00 and about $1.5 \mathrm{~Hz}$ for 13.09:30). The test indicated a loss of about $10 \%$ of the flux for either subsample. This was considered acceptable for the present study.
High-frequency spectral corrections were not used in computing the fluxes presented here. The resulting loss is less than $10 \%$, as confirmed in the implicit filtering test above. A second test, differing only in the filter used provides further confirmation. A four-pole Butterworth low-pass filter is applied forward and backward to cancel the phase shift. Four cases were simulated using data from flights 25.18:00 and 13.09:30.

1. Filter the gas series to a $2 \mathrm{~Hz}$ cutoff (half-power). This first reduction has almost no effect on 13.09:30 since it is already filtered as discussed above.

2. Filter the gas series to $2 \mathrm{~Hz}$; also filter the vertical wind to $2 \mathrm{~Hz}$. This had a small additional effect. The flux published in this paper used the full-frequency wind data.

3. Same as 1 , but filter gases to $1 \mathrm{~Hz}$.

4. Same as 2, but filter both gases and vertical wind to $1 \mathrm{~Hz}$.

All filters were implemented on the merged wind and gas data series at $50 \mathrm{~s}^{-1}$. The simulation provides an upper bound on the loss of flux above the $5 \mathrm{~Hz}$ cutoff frequency of the full gas data streams. Cutting the effective Nyquist frequency down to $2 \mathrm{~Hz}$ and then further to $1 \mathrm{~Hz}$ cuts more and more deeply into spectral ranges having increasingly significant contribution to the flux. This is reflected in the results: $10 \%$ loss at $2 \mathrm{~Hz}$ Nyquist frequency and $28 \%$ loss at $1 \mathrm{~Hz}$. The results indicate that the fraction of flux lost from frequencies higher than $5 \mathrm{~Hz}$ is less than $10 \%$. Future work will, however, include exploration of these estimation techniques.

Finally, to evaluate the dependence of the measured methane flux on the height above the ground, a regression of the $3 \mathrm{~km}$ running flux (see Sect. 2.3.1) from flight 13.09:30 was run against flight altitudes ranging from 5 to $45 \mathrm{~m}$. A quadratic regression was required, yielding a significant positive slope but significant negative curvature. The regression line reached a maximum at an intermediate point before the maximum height above ground. More importantly, the regression explained only $10 \%$ of the variance.

There were two other small instruments that augmented FOCAL's capabilities: a radar altimeter, for height above ground which is essential for accurate footprint calculations, and a visible-light camera, which provided a visual record of the terrain directly under the aircraft to check the accuracy of the remotely sensed products used for primary landscape classification. The Aurora Flight Sciences' version of the DA-42, named the Centaur, is a twin-engine aircraft which has several characteristics that make it an ideal platform for the work discussed here. The Centaur's twin-engine configuration leaves the entire center fuselage available for instrumentation and sampling. The aircraft is electrically and structurally well adapted for carrying a sophisticated scientific payload, having ample spare power from its two alternators 
and ideally located hard points for the probe and the spectroscopic equipment.

\subsection{Turbulence measurements}

Eddy covariance is a direct way to determine the exchange of mass (e.g., trace gases), momentum, and energy between the atmosphere and the surface. In principle for a gas, the covariance between the turbulent fluctuating gas concentration and the turbulent vertical wind component determines the flux. Since the flux thus obtained is assumed to represent the exchange at the surface, the airplane is flown as low as is safely possible, typically below $30 \mathrm{~m}$ (Mahrt, 1998). Flux measurements from fixed surface sites, important complements to the airborne measurements, provide extended temporal coverage at selected locations as well as validation of the airborne flux measurements.

The mass flux of a minor gas constituent in air, such as methane, is calculated following Webb et al. (1980), Gu et al. (2012). Let $\rho_{\mathrm{a}}$ be the partial density of air apart from water vapor and $w$ be the vertical wind velocity. Then $\rho_{\mathrm{a}} w$ is the dry-air mass flux, which is expanded into base state and turbulent departure with the base state represented by an overbar and the departure by a prime:

$\rho_{\mathrm{a}} w=\overline{\rho_{\mathrm{a}}}+\left(\rho_{\mathrm{a}} w\right)^{\prime}$.

Since dry air is not exchanged with the surface, $\overline{\rho_{\mathrm{a}} w}=0$. The flux of a gas is then the covariance of the turbulent dry-air mixing ratio $c^{\prime}$ with the turbulent dry-air mass flux $\left(\rho_{\mathrm{a}} w\right)^{\prime}$ :

$F=\overline{\left(\rho_{\mathrm{a}} w\right)^{\prime} c^{\prime}}$

Unlike from a stationary tower, measuring the turbulent vertical wind component from an airplane requires finding the small (vector) sum of the airspeed and the ground speed, two large, nearly canceling vectors. Since both vectors fluctuate rapidly and independently, many independent measurements must be made with precise synchrony at high accuracy and sample rate. Since turbulent fluctuations can be less than $0.1 \mathrm{~m} \mathrm{~s}^{-1}$, the two large velocities must each be accurate within $0.1 \mathrm{~m} \mathrm{~s}^{-1}$. Four samples define the minimum effectively resolvable turbulent eddy size, about $5 \mathrm{~m}$ at 50 samples per second and $60 \mathrm{~m} \mathrm{~s}^{-1}$.

\subsection{Methane flux measurements}

\subsubsection{Running flux method}

The running flux method (RFM) is commonly used in the space/time domain for eddy covariance analysis of airborne fluxes (e.g., LeMone et al., 2003). The RFM calculates the mean flux over a contiguous integration length (e.g., $3 \mathrm{~km}$ ). As opposed to a stationary tower, which averages in time, the aircraft is moving over the landscape, so that fluxes are more appropriately averages over distance. Here we use the same notation as Crawford et al. (1993)

$F=\frac{\sum_{k=1}^{N}\left(\rho_{d} w\right)_{k}^{\prime} c_{k}^{\prime} V_{k}}{\sum_{k=1}^{N} V_{k}}$,

where $\rho_{\mathrm{a}}, w^{\prime}$, and $c^{\prime}$ are defined as in Eq. (2) and $V$ is the airspeed of the aircraft. The sum is over $N$ consecutive samples, and the denominator is the spatial averaging length. For the analysis presented here we use a $3 \mathrm{~km}$ window that is moved by $1 \mathrm{~km}$ increments so that, unlike the normal practice with tower data, there is overlap between adjacent calculated fluxes to provide somewhat finer spatial localization. The RFM quantitatively describes the relationship between measured flux and underlying surface features of scales comparable to the averaging length or larger. This method works well as shown by LeMone et al. (2003), who found a $4 \mathrm{~km}$ moving average on the US Great Plains to be an appropriate compromise between uncertainty in flux estimation and resolution of landscape-scale heterogeneity. In the Arctic in 2013, the much smaller mixed layer depth gave rise to smaller turbulence scales. Ogive analysis of the frequency distribution showed $3 \mathrm{~km}$ to suffice as the integration distance (Berger et al., 2001). However, heterogeneity in the resulting flux estimates was large. Repeated flight segments gave variable results likely due to changes in winds and sampling footprints and to the integration lengths being longer than the scale of the underlying surface features. Nevertheless, there was good agreement between methane fluxes calculated by the RFM using $3 \mathrm{~km}$ integration centered near the tower location and fluxes computed directly from the tower measurements (see Sect. 3.1). Using the RFM over the small-scale heterogeneity of the North Slope's surface features, however, limits the ability to isolate the flux contributions from individual surface classes.

\subsubsection{Flux fragment method}

The flux fragment method (FFM) was conceived to assess the homogeneity in properties of a remotely determined land class over multiple instances occurring in patches on the landscape. Often such patches are too small for a traditional RFM (Kirby et al., 2008). The FFM, while based on the same statistical foundation as eddy covariance, uses a conditional sampling scheme whereby the flux, of methane for example, is compiled from many $\tau \mathrm{s}$ "fragments" $f_{i}$ of methane fluxes along a transect, each given by

$$
\begin{aligned}
f_{i} & =\delta t \sum_{k=1}^{n \tau}\left[\left(\rho_{d} w\right)_{k}^{\prime} c_{k}^{\prime} V_{k}\right]_{i}, \\
L_{i} & =\delta t \sum_{k=1}^{n \tau}\left[V_{k}\right]_{i} .
\end{aligned}
$$

Here $n$ is the number of samples per second, $\delta t$ is the sample interval, and everything else is defined as in Eq. (3) except that instead of summing over a large distance, such as 


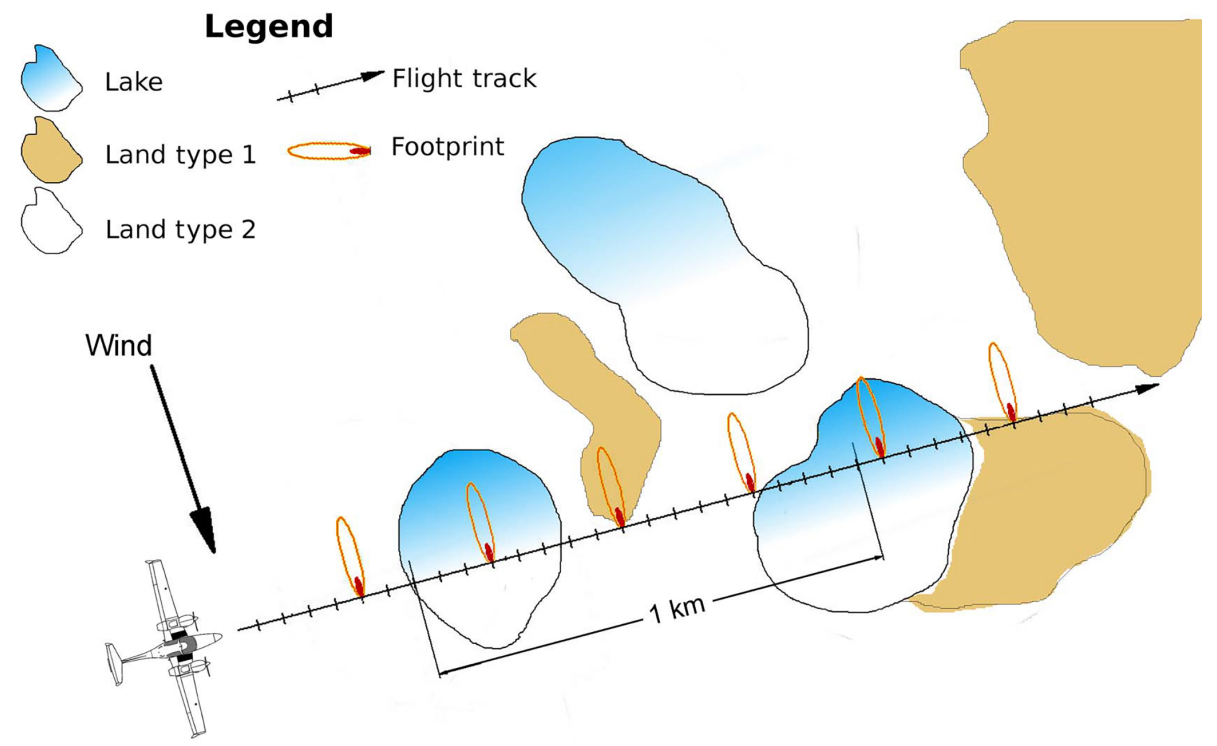

Figure 3. The flux fragment method (FFM) divides the covariance measurements into small fragments whose footprints can be attributed to different landscape features or classes. In the figure the landscape has been divided into lakes and two types of land, for example wet sedge and fresh water marsh. Footprints are calculated for each fragment and footprints that lie mostly (>85\%) on a single land type are assigned to that land type. All footprints for a given land type can then be summed and divided by the cumulative path length in air.

$3 \mathrm{~km}$, the sum is only over a few samples. Note, however, that the departure quantities used to form the fragments are relative to the same base state as in Eq. (3), a base state of $3 \mathrm{~km}$ scale or more, determined by ogive analysis (Foken, 2008) to be an upper limit for the turbulence present at the time of measurement. The fragments therefore contain information on all scales from the Nyquist wavelength of the sample rate up to the $3 \mathrm{~km}$ scale of the spectral gap determined from the ogive analysis. However, the air packets quantified by the fragments are also short enough to have likely interacted with a single surface class. So long as any significant secondary circulations are accounted for in the base state, the turbulent atmosphere on all its scales can be postulated to repeat over the landscape in a fairly random fashion. A contiguous sample (i.e, without gaps) should not therefore be required. The sample only needs to be sufficiently large to include multiple instances of boundary layer structures at each scale. An aircraft moving at airspeed $60 \mathrm{~m} \mathrm{~s}^{-1}$ covers $216 \mathrm{~km}$ in an hour encountering 72 instances of $3 \mathrm{~km}$ turbulence structure. A sufficiently prevalent land surface class, whether found in large or small patches is very likely to provide a sufficient sample. Samples which are too short can be discovered in confidence intervals developed by bootstrap resampling as was done by Kirby et al. (2008). A more sophisticated bootstrap procedure developed in conjunction with analysis of these 2013 data by Dobosy et al. (2017) follows Mudelsee (2010).

In the data presented here the fragments are $1 \mathrm{~s}$ sums $(\tau=$ $1 \mathrm{~s})$ of approximately $60 \mathrm{~m}$ length. The fragments, labeled $f_{i}$, do not constitute a Reynolds average individually. That is, an individual fragment, though containing all turbulent scales, is only a short grab sample. Fragments provide a meaningful flux estimate only in aggregate. They can be grouped, for example, by land-surface class, determined from footprint estimation (Fig. 3). Fluxes are calculated only for those landsurface-class groups whose total length is greater than $3 \mathrm{~km}$. The sum over each group divided by the cumulative length of all fragments in the group provides the mean flux from the associated land-surface class as given by

$F_{S}=\frac{\sum_{i \in S} f_{i}}{\sum_{i \in S} L_{i}}$.

The FFM is most appropriate in a region that is heterogeneous on small scales ( $100 \mathrm{~m}$ to $3 \mathrm{~km}$ ), but relatively homogeneous on large scales such that many instances of the surface class, or other classification used to group the fragments, are sampled during the flight (see Kirby et al., 2008 for the full description of the method). Initial assessments of the data presented here indicate that the FFM is well suited for application to the North Slope, where Arctic tundra is interspersed with thermokarst lakes, bogs, fens and bare ground. First, land-cover data are classified using a current land-cover image at $100 \mathrm{~m}$ resolution or better (e.g., LandSat). We use this to establish transects flown at altitudes typically 10 to $30 \mathrm{~m}$ above ground; as low as safely possible. These are flown repeatedly and coordinated with eddy covariance towers for validation and temporal continuity. The base state is then defined, representing in principle the deterministic (nonturbulent) mesoscale component of the flow. Flux fragments are calculated using $1 \mathrm{~s}$ sums of squares and cross products 


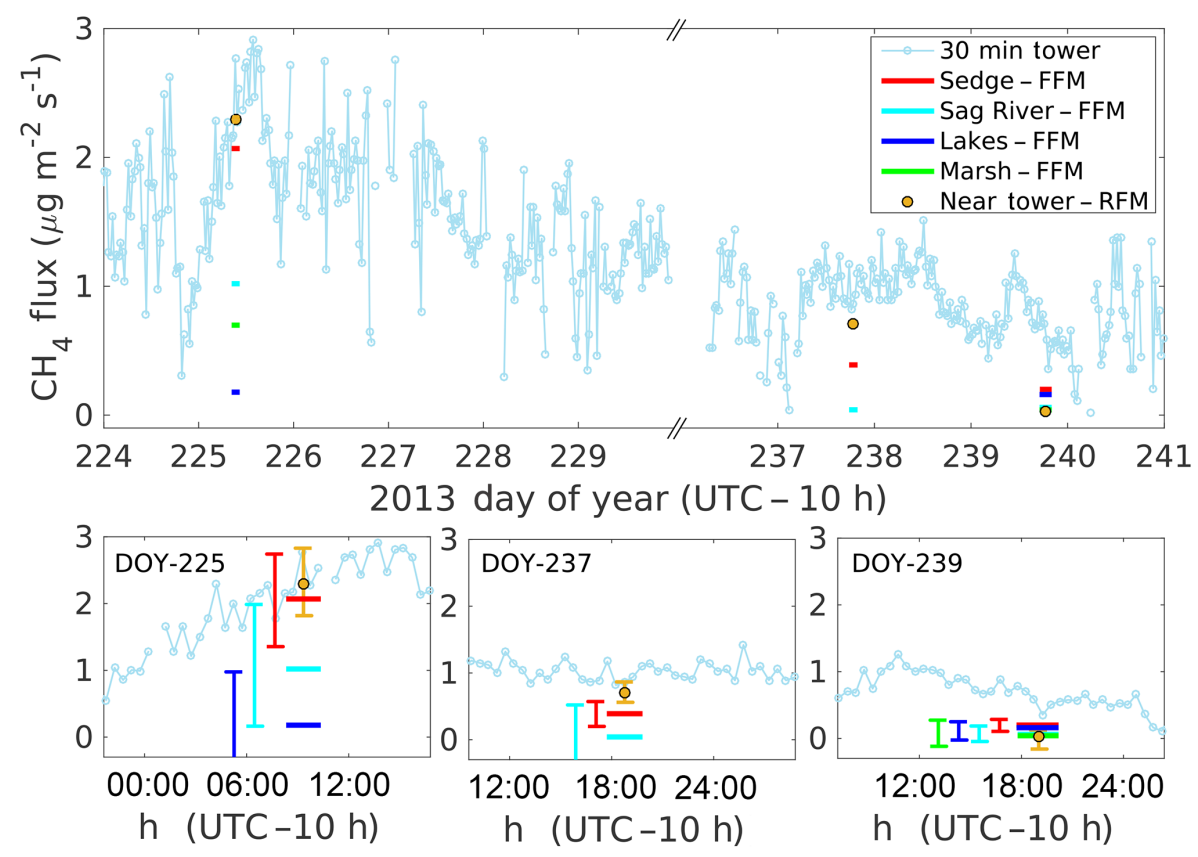

Figure 4. Methane fluxes measured from the flux tower compared with fluxes measured by the FOCAL system. Tower methane fluxes (top plot) are 30 min means plotted versus day of year. The flights (13.09:30, 25.18:00, and 27.19:00 on DOY 225, 237, and 239, respectively) each included repeated passes near the tower. The orange circle gives the mean over these passes of the RFM-determined $3 \mathrm{~km}$ flux centered nearest the tower. Fluxes by FFM were aggregated by surface class over the whole flight. The length of the line along the time axis represents the period over which the data were taken, typically $1.5 \mathrm{~h}$. Lower panels show details for each flight day, labeled by day of year (DOY), with vertical bars showing the $95 \%$ confidence interval based on bootstrap analysis. Bars are offset along the $x$ axis for clarity.

of departures from the base state. Finally, a footprint model is applied to estimate the level of influence of each surface class on each fragment. See Sect. 3.2 for examples of how FFM is used to interpret these data.

For the questions to be addressed in this paper the footprint model provides a measure of a fragment's membership in the fuzzy set (Nguyen and Walker, 2000) associated with each surface class, treated as a categorical variable. Fragments having a sufficient level of membership for a particular surface class are assigned to that class. Setting the membership criterion above 0.5 restricts all fragments to a maximum of one class. A meaningful subset of the available fragments, further grouped into non-intersecting subsets according to their primary surface of origin, can thus be obtained.

We use the parameterization scheme developed by Kljun et al. (2004) from a set of runs of a backward Lagrangian model (Kljun et al., 2002) for a range of heights, stability measures, and other turbulence quantities that are measured from the aircraft. The required turbulence quantities are computed from averages taken over the length of each flight leg, where the flight leg is defined as the straight segment, between turns, over which the collected data are used. The more recent 2-D version (Kljun et al., 2015), which was considered too computationally intensive to be included in the present study, was not considered necessary because of the footprint's current restricted use as a membership criterion to assign a selected subset of fragments to the surface categories. The degree of overlap was assessed, however, for future reference. Using the measurements from the convective daytime case 13.09:30, the 2-D model yielded a footprint with a full width of about $250 \mathrm{~m}\left( \pm 1 \sigma_{y}\right)$ at the location of maximum crosswind-integrated probability, $93 \mathrm{~m}$ upwind of the sensors. Since the probabilities are weighted towards the middle of the footprint and the land classes tend to be homogeneous on the order of at least $300 \mathrm{~m}$, using the 1D version of the model is acceptable given our focus on categorical classification and our strict membership criterion (85\%). With interval quantities the weighted distribution of sources over the full 2-D footprints will be required.

The flux estimate for each land surface class is the sum of the fragments in the associated group divided by their accumulated length. The number of fragments necessary to provide a robust result can be determined by bootstrap resampling (Kirby et al., 2008). For the data presented here $3 \mathrm{~km}$ or $\sim 50$ fragments suffice.

The questions to be answered by the FFM, using a fuzzylogic approach (Nguyen and Walker, 2000) to assign surface classes to fragments and then to conditionally sample them based on those classes, are the following:

1. What is the mean flux over all measured instances of each surface class? 

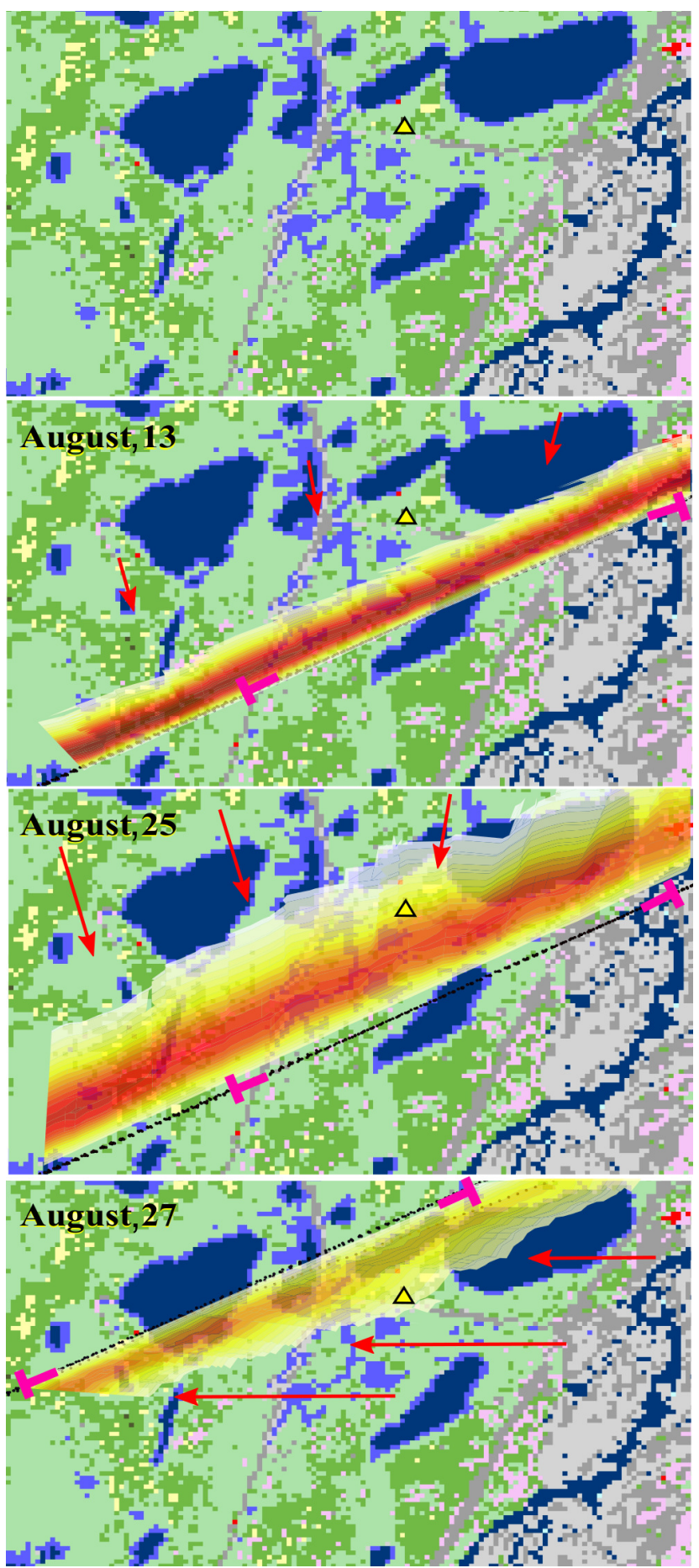

Figure 5. Flux footprints near the tower (yellow triangle) for the three tower flights (13.09:30, 25.18:00, and 27.19:00). They are laid over the NSSI-classified land-cover map (see Fig. 2). The top panel facilitates identifying the surface classes under each footprint. The flight track, always passing downwind of the tower, is shown as black points, each giving the starting position of a flux fragment. The darker and redder ribbon color represents greater probability of contribution to the total flux as described in the text. Red arrows indicate the mean direction of the wind. The part of the flight track used in the near-tower RFM calculation is located between the magenta brackets.
2. What surface classes dominate the methane emissions, and by how much?

3. How much does the flux over each class vary? Is there a spatial pattern to the variation? The variability will come both from the prevailing atmospheric environment and the heterogeneity of the emissions within the same class.

4. How well does a particular instance represent all similar instances over the landscape?

\subsection{Land surface classification}

The land surface on the North Slope can be divided into different classes based on dominant plant species, topography, soil content, and soil moisture. The North Slope Science Initiative (NSSI) has identified 24 classes using Landsat Thematic Mapper (TM) $30 \mathrm{~m}$ resolution land-cover maps in conjunction with field surveys (Initiative, 2013). These classifications are plausible proxies for properties that have been shown to be primary drivers of methane production and emission, including water table height, soil temperature, and emission pathways such as sedge roots. The areas sampled by FOCAL (Fig. 2) were covered by patches of wet sedge, mesic sedge - dwarf shrub, fresh water marsh, tussock tundra, and open water. Open water is visible from the air, and includes lakes of various sizes and origin along with rivers. Coastal waters, however, are excluded for this analysis. By definition in the tussock tundra land class, shrubs more than $20 \mathrm{~cm}$ tall occupy less than $25 \%$ of the surface, and tussocks occupy more than $35 \%$. The sites are cold, poorly drained and underlain by moderately moist (mesic) to wet mineral soils with silty to sandy texture and a shallow surface organic layer surrounding the tussocks. Wet sedge sites are defined as those with sedge species accounting for more than $25 \%$ of the cover and Sphagnum for less than $25 \%$. Soils range from acidic to non-acidic, are saturated during the summer, and typically have an organic layer over silt or sand. Mesic sedge-dwarf shrub has shrubs less than $25 \mathrm{~cm}$ tall covering more than $25 \%$ of the area, and sedge cover is also more than $25 \%$. Soil surface is generally mesic, but sometimes wet and is calcareous to acidic. The fresh water marshes (FWM) are semi-permanently flooded, but some have seasonal flooding, and the water depth typically exceeds $10 \mathrm{~cm}$. Soils are muck or mineral, and the water can be nutrient-rich.

We use land classes defined by a remote measurement, as opposed to soil properties such as moisture, organic carbon content, temperature, etc. because the remotely based definition is more appropriate to comparing to larger regional-scale models and satellites. Thus the land class here is usually a proxy for general classifications of areas with different soil moisture and other properties which are likely the primary drivers of differences in methane emissions. Certain plants such as sedge, however, have been shown to act as conduits directly facilitating methane release from the soil to the at- 


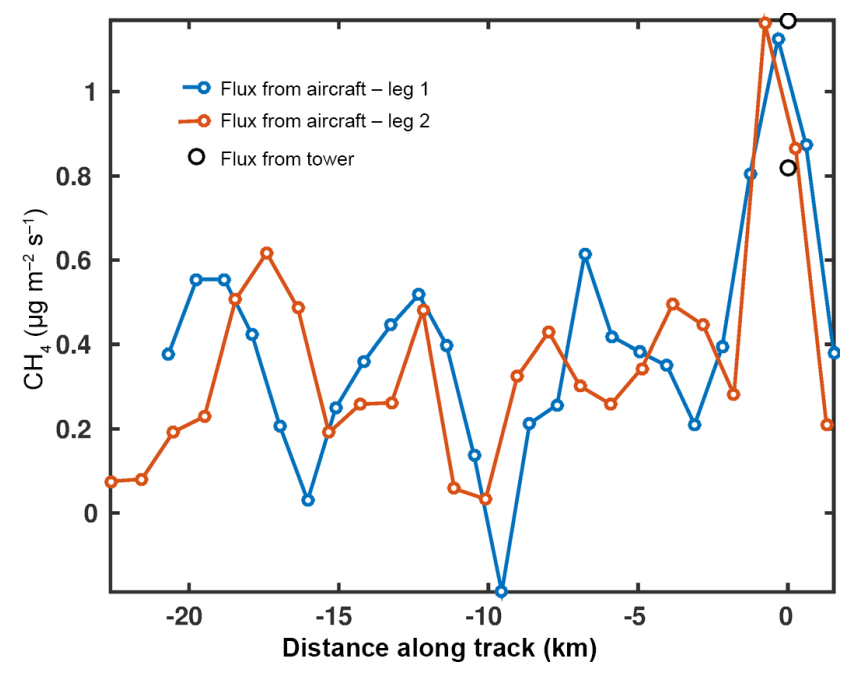

Figure 6. Plot of methane flux derived using RFM versus distance from flux tower for two flight legs on 25 August. Positive (negative) distance is east (west) of the tower position. The east to west transect (blue) was flown 30 min after the west to east transect (orange). Black circles are the methane flux measured by the tower at the time nearest to when the aircraft passed the tower.

mosphere through the plants' vascular system (Olefeldt et al., 2013).

In order to distinguish the contribution to the total methane flux from individual land classes and to assess the variability across ecotopes, the data are filtered to only include flux fragments having a membership score of at least $85 \%$, determined by integrating the length of the footprint's centerline weighted by the crosswind-integrated probability density that the flux came from a single surface class. Increasing this threshold increases the link between the calculated flux and a single land class, but reduces the number of footprints available for the analysis, thus widening the confidence interval. Varying the threshold between 80 and $95 \%$ produces only a small effect on the quantification of flux from each land class. We find that $85 \%$ is a good compromise between singling out individual land classes while still retaining a sufficient data set. For the flight speed of the Centaur at low altitude and wind conditions during the flights, the length of the footprint contributing more than $90 \%$ of the flux for each $60 \mathrm{~m}$ fragment varied between 100 and $800 \mathrm{~m}$. The above filter eliminates about a third to half of the flux fragments from each flight. Of those, we limit the land classes to those where the total number of flux fragments is more than 50 fragments or an equivalent distance of $3 \mathrm{~km}$. The flux fragments are summed and then divided by the total integration length for each land class (Fig. 7).

\subsection{Tower measurements}

Starting a few weeks before the flight campaign and throughout the month of August, a small portable flux tower was

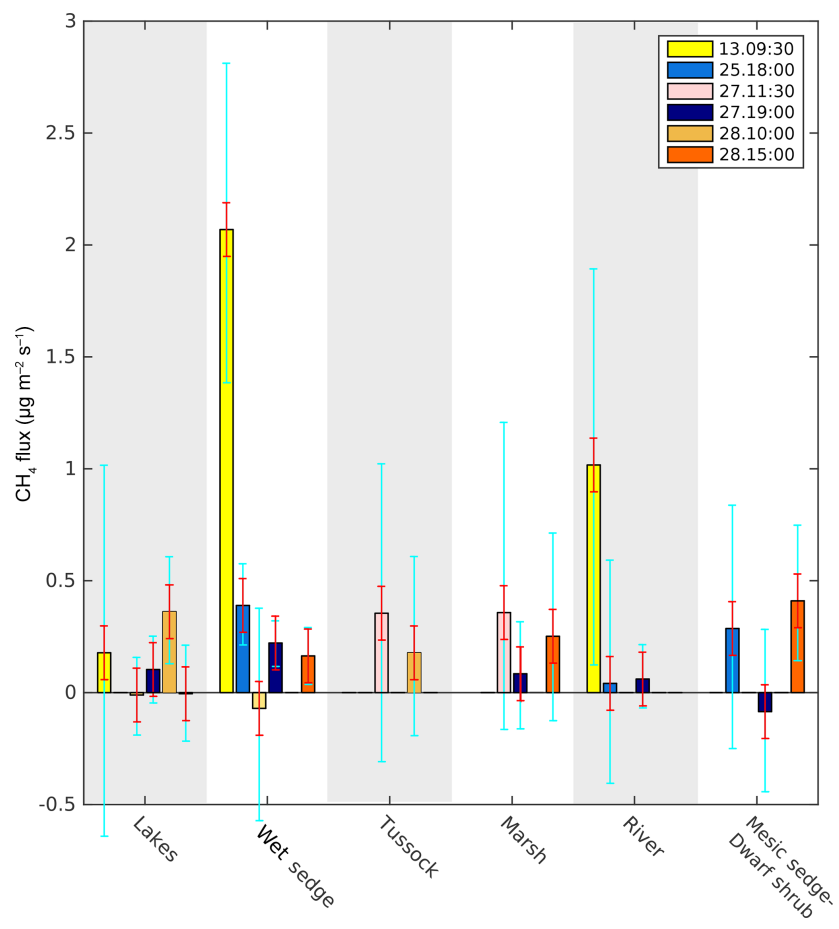

Figure 7. Mean methane fluxes by land surface class derived using the FFM for each of six flights as given in the legend. Dates of flights are given as day of month in August followed by the time of the middle of the flight. Bars give the instrument uncertainty (red) and the $95 \%$ confidence interval as calculated using bootstrapping (blue).

installed at $70.08545^{\circ} \mathrm{N}, 148.57016^{\circ} \mathrm{W}$, just south of Prudhoe Bay off the Dalton Highway. During that time the tower recorded $\mathrm{CO}_{2}$ flux, $\mathrm{CH}_{4}$ flux, latent heat flux, sensible heat flux, air temperature, and incoming radiation. Soil temperature probes were used to record soil temperature at 2,5 , 10 , and $20 \mathrm{~cm}$ depth at three different locations around the tower. The tower was situated in an area dominated by sedge grass, and the surrounding area's water table was frequently near the surface such that the surroundings were puddled and muddy, especially in late August 2013. On the NSSI map the area is labeled as wet sedge. Low light and limited convective mixing are common on the North Slope of Alaska, and data collected in very weak winds do not provide reliable eddy covariance flux measurements. Consequently, data were removed from the final set when the standard deviation of the vertical wind speed was less than $0.1 \mathrm{~m} \mathrm{~s}^{-1}$.

\section{Results and discussion}

\subsection{Comparison between aircraft and tower fluxes}

On 13, 25, and 27 August the FOCAL aircraft flew repeated passes over a constant northeast/southwest track near the tower affording direct comparison between eddy covariance 
methane fluxes measured from the tower and from the moving aircraft in both RFM and FFM modes (Fig. 2). The flight track was displaced north or south depending on the forecast wind direction so that the aircraft footprint could pass over the tower footprint. For the northerly winds on 13 and 25 August, the flight track was displaced south of the tower. For the easterly winds of 27 August the track passed north of the tower.

Two factors, diurnal and seasonal, influenced the fluxes at the tower site (Fig. 4). The flight 13.09:30 on 13 August (DOY 225) was in the daytime earlier in August, when the turbulence was stronger and the soil temperatures at $10 \mathrm{~cm}$ depth were $10-14{ }^{\circ} \mathrm{C}$. The 30 min mean methane fluxes at the tower ranged from 1 to $2.5 \mu \mathrm{g} \mathrm{m}^{-2} \mathrm{~s}^{-1}$. The flights 25.18:00 and 27.19:00 on 25 and 27 August (DOY 237 and 239) were in the evening and later in August with weaker turbulence and lower soil temperatures of $3-6^{\circ} \mathrm{C}$ at $10 \mathrm{~cm}$ depth. Most $30 \mathrm{~min}$ mean methane fluxes ranged from 0.5 to $1.3 \mu \mathrm{g} \mathrm{m}^{-2} \mathrm{~s}^{-1}$. The observed variation with soil temperature is consistent with previous studies (e.g., Yvon-Durocher et al., 2014). Aircraft methane fluxes were compared with the tower in two modes: as local RFM, the mean over all transects of a flight of the $3 \mathrm{~km}$ flux blocks downwind of and centered nearest to the tower, and as FFM, the mean of the fragments from wet sedge gathered from the whole $50 \mathrm{~km}$ transect and the whole flight.

Agreement between the aircraft and tower by local RFM (orange circle), near the tower but not differentiated by surface class, is within the confidence intervals of the data from 13.09:30 and 25.18:00. For 27.19:00 the aircraft measured significantly lower methane flux by local RFM than the tower. By FFM from wet sedge (red line), the same surface class as the tower but not local to it, the methane flux from 13.09:30 agrees very well with the magnitude of the flux measured on 13 August at the tower. However, for 25.18:00 the FFM flux from wet sedge is significantly lower than the 25 August tower measurement. It is likewise for 27.19:00, though the FFM flux over wet sedge is closer to the corresponding tower flux on 27 August than is the flux calculated by the local RFM.

The results from the three near-tower flights represent three different situations. On 27 August (flight 27.19:00), the footprint of the airborne measurement (Fig. 5, bottom panel) differed from that of the tower. On that flight the footprint analysis indicates the highest probability of influence on the RFM flux (red to maroon contours in Fig. 5) to be over open water, not wet sedge, for at least half the range (the $3 \mathrm{~km}$ length centered nearest to the tower in the downwind direction). Lakes have been shown to be sporadic hotspots of methane ebullition, but at least at the time of flight these lakes showed very low methane emissions. On 27 August, the sedge, which makes up more than twice as much of the transect as the lakes, is visible to the FFM, but not to the local RFM near the tower. Also, the turbulence on August 27.19:00 was weak, with $\sigma_{w} \sim 0.15 \mathrm{~m} \mathrm{~s}^{-1}$. This is a case where some signal may have been lost due to insufficient sample rate for the altitude, or perhaps because the measurement was made above the shallow layer of "constant" flux. This is a tradeoff that plagues evening and morning flights. Notable about flight 27.19:00 is its demonstration of the need for, and difficulty of obtaining, matching footprints when comparing flux measurements from different instruments.

On 25 August, the local RFM produced a good match with the tower, in contrast to the (distributed) FFM. Plotting the entire set of RFM fluxes from 25.18:00 yielded a surprise (Fig. 6), where the tower appears to be in a local hotspot. This may also be the case on August 27.19:00, where the flux from the wet sedge around the tower is stronger than the FFM flux from the wet sedge measured by the aircraft. Plots of methane flux against the height of airborne measurement and the strength of turbulence $\left(\sigma_{w}\right)$ suggested no simple dependence on these. This flight dramatically shows the hazards inherent in relying on point measurements, which are potentially in non-representative locations, to estimate the area-wide flux. Also note in the middle lower panel of Fig. 4 that the flux of $1 \mu \mathrm{g} \mathrm{m}^{-2} \mathrm{~s}^{-1}$ at the tower, though isolated in space, was not isolated in time.

On 13 August everything matched. For flight 13.09:30 the wind was light and the mixing strong $\left(\sigma_{w} \sim 0.45 \mathrm{~m} \mathrm{~s}^{-1}\right)$. The warm soil produced a strong methane flux, and the methane flux measured at the tower matched the local RFM flux near the tower as well as the FFM flux from the distributed patches of wet sedge. Importantly, both the summer daytime (13.09:30) and autumn evening (25.18:00) flights showed that when there is reasonable overlap between the tower and aircraft footprints, the flux measurements from the aircraft agree with those from the tower adding another level of validation to the aircraft data.

\subsection{Regional methane fluxes}

During August 2013 FOCAL measured methane fluxes from a variety of ecotopes across the North Slope. There are six flights used in this analysis; four in the daytime and two in the evening (18:00-19:00 UTC -10) which were covered individually in the last section. Keeping that discussion in mind, these data are comparable as a set. Based on the tower data, which exhibit strong and regular diurnal cycles of carbon dioxide and latent heat (not shown), methane has a generally weak diurnal cycle. The sharp feature in the tower trace on 13 August (DOY 225) very likely has a diurnal component, but its shape suggests more than just solar input. This discussion, therefore, will focus on the seasonal change and the methane emission characteristics of the various surface classes (Figs. 4 and 7).

The land cover varies over the North Slope, so different flights sampled different classes of land cover (see Table 1 and Fig. 2). Wet sedge was the most prevalent and thus was sampled on each flight, except for flight 28.10:00 on the morning of 28 August. Other land surface classes such as 
bare ground, dwarf shrub, and low-tall willow were also observed but in insufficient quantity to calculate a statistically significant flux. Prevalent near the tower site, which was sampled on 13, 25, 27 August, were wet sedge, mesic sedgedwarf shrub, some lakes, the Sagavanirktok (Sag) River, and fresh water marsh. Soil temperatures in mid-August varied by $1.5^{\circ} \mathrm{C}$ with a mean soil temperature of $8{ }^{\circ} \mathrm{C}$ at $5 \mathrm{~cm}$ depth. By the end of August soil temperatures had dropped to a mean of $3{ }^{\circ} \mathrm{C}$. Wet sedge showed the strongest correlation with soil temperature, with fluxes falling from $2.1 \mu \mathrm{g} \mathrm{m}^{-2} \mathrm{~s}^{-1}$ on 13 August to less than $0.5 \mu \mathrm{g} \mathrm{m}^{-2} \mathrm{~s}^{-1}$ by the end of August. This relationship held true for emissions from the Sag River with emissions falling from $1 \mu \mathrm{g} \mathrm{m}^{-2} \mathrm{~s}^{-1}$ to near 0 . Wet sedge, followed by the Sag River, had the largest observed flux of any of the land classes sampled during the first half of August. The other land classes have smaller, more variable fluxes on most flights so that surface class alone does not distinguish them. Most likely the true variability, contributing to the large confidence intervals, is caused by heterogeneity within the surface class in sub-surface soil temperature and water table height. However, within that we can still derive a mean flux based on a large regional sample. Once the soil cools, wet sedge shows reduced, though still positive, flux of methane consistent with the other surface classes measured such as mesic sedge and lakes. The Sag River shows close to zero methane flux. Lakes showed no trend. It should be noted, however, that the number of lakes sampled on $13 \mathrm{Au}-$ gust was small and the flux variable as indicated by the large $95 \%$ confidence interval. While data from the other land classes sampled on 13 August were sparse, emissions from fresh water marsh and tussock tundra during the second half of August were similar to those from lakes and the two sedge classes.

Airborne measurements made during August 2013 are consistent with findings from other studies. Olefeldt et al. (2013) reported sites dominated by sedge and wet soils having methane emissions ranging from 0.46 to $1.6 \mu \mathrm{g} \mathrm{m}^{-2} \mathrm{~s}^{-1}$ with a median value of $0.87 \mu \mathrm{g} \mathrm{m}^{-2} \mathrm{~s}^{-1}$ across multiple permafrost sites. Other studies at single locations fall into this same range. For example, Harazono et al. (2006) measured methane fluxes from a wet sedge site in Happy Valley, AK during August of 1995 ranging from 0.38 to $1.5 \mu \mathrm{g} \mathrm{m}{ }^{-2} \mathrm{~s}^{-1}$ and Sturtevant and Oechel (2013) measured wet sedge near Barrow with emissions of $0.39 \pm 0.03 \mu \mathrm{g} \mathrm{m}^{-2} \mathrm{~s}^{-1}$ with short periods of higher emissions up to $1.1 \mu \mathrm{g} \mathrm{m}^{-2} \mathrm{~s}^{-1}$. Emissions from mesic sedge sites near the Sag River, though south of the areas measured by FOCAL, showed fluxes of 0.35 to $0.58 \mu \mathrm{g} \mathrm{m}^{-2} \mathrm{~s}^{-1}$ in the first half of August falling to 0.12 to $0.23 \mu \mathrm{g} \mathrm{m}^{-2} \mathrm{~s}^{-1}$ in the second half of August (Harazono et al., 2006).

Emissions from lakes tend to be more variable than the land classes. Measured emissions from individual lakes ranged from 0.25 to $6.3 \mu \mathrm{g} \mathrm{m}^{-2} \mathrm{~s}^{-1}$ across various thermokarst and other lakes in the North Slope (Walter et al., 2007a; Sepulveda-Jauregui et al., 2015). These fluxes are re- ported as means over a year, so emission rates during short periods of time may be lower or higher for an individual lake. While FOCAL did not sample the same lakes as in the aforementioned studies, during the flights near the tower, multiple passes over the same lakes allowed for measuring emissions from individual lakes. On 13 August, five lakes were sampled with sufficient frequency to produce a statistically significant flux. The flux for individual lakes ranged from 0 to $2.6 \mu \mathrm{g} \mathrm{m}^{-2} \mathrm{~s}^{-1}$ with a mean for all lakes sampled of $0.18 \mu \mathrm{g} \mathrm{m}^{-2} \mathrm{~s}^{-1}$. On 27 August four lakes were measured with emissions ranging from 0.09 to $0.18 \mu \mathrm{g} \mathrm{m}^{-2} \mathrm{~s}^{-1}$. The mean methane flux from lakes over the period of the flights shows little flux, except for the lakes sampled on the morning flight of 28 August. These are in a different area $250 \mathrm{~km}$ west of the tower. Those lakes show an aggregate mean of $0.36 \mu \mathrm{g} \mathrm{m}^{-2} \mathrm{~s}^{-1}$, the only flux measured from lakes that was statistically significantly positive (Fig. 7). These data are consistent with the rates measured by the above studies.

\section{Conclusions}

The FOCAL campaign during the summer of 2013 showed how methane fluxes could be successfully measured over large regions using airborne eddy covariance measurements from a small, low-flying aircraft. The data were analyzed in the space/time domain with both a running flux method using traditional eddy covariance and the flux fragment method (FFM), a variant using a conditional sampling scheme. Other techniques such as wavelet analysis that rely on the frequency domain to look at the same questions would be worth exploring in the future. A comparison of the theory behind FFM with the theory behind the wavelet method is included in Dobosy et al. (2017).

Comparison of the airborne measurements to those of a tower showed that the data were quantitatively comparable when there was good overlap between the tower footprint and aircraft footprint. However, along the flight track local conditions dominated the flux especially in the transition season from summer to fall in late August. Comparing wet sedge at the tower site with wet sedge west of the tower showed a factor of 2 difference in methane emissions during the latter half of August which underscores the importance of regional measurements as fluxes can be heavily dependent on spatial heterogeneity even over relatively short distances. During the middle of the summer fluxes from wet sedge were more homogeneous across the area flown.

Measurements of methane fluxes over the North Slope of Alaska in August showed a strong correlation with soil temperature consistent with previous studies. Wet sedge showed the highest persistent methane emissions with mean fluxes about $2 \mu \mathrm{g} \mathrm{m}^{-2} \mathrm{~s}^{-1}$ in the first half of August falling to $0.2 \mu \mathrm{g} \mathrm{m}^{-2} \mathrm{~s}^{-1}$ in the latter half of August. Emissions from the Sag River showed a similar trend, while other land surface classes were not sampled enough during the first half 
of August to provide a statistically significant sample. Individual lakes sampled near the tower showed a large range of emissions varying from near 0 to $2.6 \mu \mathrm{g} \mathrm{m}^{-2} \mathrm{~s}^{-1}$ consistent with the range of lake emissions reported in the literature.

Aircraft measurements of surface flux can play an important role in bridging the gap between ground-based measurements and regional measurements based on inversion modeling or budget-box models. While airborne campaigns are generally more costly than ground-based measurements, these costs can be minimized by using small aircraft. For areas that are logistically challenging to access, such as the North Slope, airborne eddy covariance presents the easiest and least expensive way to directly measure surface fluxes regionally with large coverage.

Data availability. All data are publicly archived at the NSF ACADIS website (https://doi.org/10.18739/A2JW84, Sayres and Dobosy, 2013) under citation David Sayres, 2014. Collaborative Research: Multi-Regional Scale Aircraft Observations of Methane and Carbon Dioxide Isotopic Fluxes in the Arctic. NSF Arctic Data Center. urn:uuid:58bddf69-74fe-4a20-958e-4cd23bb6941f.

Competing interests. The authors declare that they have no conflict of interest.

Acknowledgements. This work was supported by NSF grant 1203583 and data are archived on the ACADIS website. The authors wish to gratefully acknowledge the efforts and exceptional flying of our pilot, Bernard "Bernie" Charlemagne, without whom these data could not have been collected.

Edited by: Janne Rinne

Reviewed by: two anonymous referees

\section{References}

Avissar, R., Holder, H. E., Abehserra, N., Bolch, M. A., Canning, P., Magalhaes, J., Walko, R. L., Novick, K., Katul, G., Prince, K., Matayoshi, N., and Johnson, K. M.: The Duke University Helicopter Observation Platform, B. Am. Meteorol. Soc., 90, 939954, 2009.

Bange, J., Spiess, T., and van den Kroonenberg, A.: Characteristics of the early-morning shallow convective boundary layer from Helipod Flights during STINHO-2, Theor. Appl. Climatol., 90, 113-126, https://doi.org/10.1007/s00704-006-0272-2, 2007.

Bastviken, D., Cole, J., Pace, M., and Tranvik, L.: Methane emissions from lakes: Dependence of lake characteristics, two regional assessments, and a global estimate, Global Biogeochem. Cy., 18, GB4009, https://doi.org/10.1029/2004GB002238, 2004.

Berger, B. W., Davis, K. J., Yi, C. X., Bakwin, P. S., and Zhao, C. L.: Long-term carbon dioxide fluxes from a very tall tower in a northern forest: Flux measurement methodology, J. At- mos. Ocean. Tech., 18, 529-542, https://doi.org/10.1175/15200426(2001)018<0529:LTCDFF>2.0.CO;2, 2001.

Boucher, O., Friedlingstein, P., Collins, B., and Shine, K. P.: The indirect global warming potential and global temperature change potential due to methane oxidation, Environ. Res. Lett., 4, 044007, https://doi.org/10.1088/1748-9326/4/4/044007, 2009.

Casper, P., Maberly, S. C., Hall, G. H., and Finlay, B. J.: Fluxes of methane and carbon dioxide from a small productive lake to the atmosphere, Biogeochemistry, 49, 1-19, https://doi.org/10.1023/A:1006269900174, 2000.

Chang, R. Y. W., Miller, C. E., Dinardo, S. J., Karion, A., Sweeney, C., Daube, B. C., Henderson, J. M., Mountain, M. E., Eluszkiewicz, J., Miller, J. B., Bruhwiler, L. M. P., and Wofsy, S. C.: Methane emissions from Alaska in 2012 from CARVE airborne observations, P. Natl. Acad. Sci. USA, 111, 16694-16699, https://doi.org/10.1073/pnas.1412953111, 2014.

Crawford, T. L. and Dobosy, R. J.: A Sensitive Fastresponse Probe To Measure Turbulence and Heat-flux From Any Airplane, Bound.-Lay. Meteorol., 59, 257-278, https://doi.org/10.1007/BF00119816, 1992.

Crawford, T. L. and Dobosy, R. J.: Pieces to a puzzle: Air-surface exchange and climate, GPS World, 8, 32-39, 1997.

Crawford, T. L., McMillen, R. T., Dobosy, R. J., and MacPherson, I.: Correcting airborne flux measurements for aircraft speed variation, Bound.-Lay. Meteorol., 66, 237-245, 1993.

Crawford, T. L., Dobosy, R. J., and Dumas, E. J.: Aircraft wind measurement considering lift-induced upwash, Bound.-Lay. Meteorol., 80, 79-94, https://doi.org/10.1007/BF00119012, 1996.

Damm, E., Helmke, E., Thoms, S., Schauer, U., Nöthig, E., Bakker, K., and Kiene, R. P.: Methane production in aerobic oligotrophic surface water in the central Arctic Ocean, Biogeosciences, 7, 1099-1108, https://doi.org/10.5194/bg-7-1099-2010, 2010.

Dobosy, R., Dumas, E. J., Senn, D. L., Baker, B., Sayres, D. S., Witinski, M. F., Healy, C., Munster, J., and Anderson, J. G.: Calibration and quality assurance of an airborne turbulence probe in an aeronautical wind tunnel, J. Atmos. Ocean. Tech., 30, 182196, https://doi.org/10.1175/JTECH-D-11-00206.1, 2013.

Dobosy, R., Sayres, D., Healy, C., Dumas, E., Heuer, M., Kochendorfer, J., Baker, B., and Anderson, J.: Estimating random uncertainty in airborne flux measurements over Alaskan tundra: Update on the Flux Fragment Method, J. Atmos. Oceanic Technol., https://doi.org/10.1175/JTECH-D-16-0187.1, in press, 2017.

Engel, G. S., Drisdell, W. S., Keutsch, F. N., Moyer, E. J., and Anderson, J. G.: Ultrasensitive near-infrared integrated cavity output spectroscopy technique for detection of $\mathrm{CO}$ at $1.57 \mathrm{mu} \mathrm{m}$ : new sensitivity limits for absorption measurements in passive optical cavities, Appl. Optics, 45, 9221-9229, 2006.

Foken, T.: The energy balance closure problem - An overview, Ecol. Appl., 18, 1351-1367, 2008.

Gioli, B., Miglietta, F., De Martino, B., Hutjes, R. W. A., Dolman, H. A. J., Lindroth, A., Schumacher, M., Sanz, M. J., Manca, G., Peressotti, A., and Dumas, E. J.: Comparison between tower and aircraft-based eddy covariance fluxes in five European regions, Agr. Forest Meteorol., 127, 1-16, 2004.

Gioli, B., Miglietta, F., Vaccari, F. P., Zaldei, A., and De Martino, B.: The Sky Arrow ERA, an innovative airborne platform to monitor mass, momentum and energy exchange of ecosystems, Ann. Geophys., 49, 109-116, 2006. 
Gu, L., Massman, W. J., Leuning, R., Pallardy, S. G., Meyers, T., Hanson, P. J., Riggs, J. S., Hosman, K. P., and Yang, B.: The fundamental equation of eddy covariance and its application in flux measurements, Agr. Forest Meteorol., 152, 135-148, 2012.

Harazono, Y., Mano, M., Miyata, A., Yoshimoto, M., Zulueta, R., Vourlitis, G., Kwon, H., and Oechel, W. C.: Temporal and spatial differences of methane flux at arctic tundra in Alaska, Mem. Natl Inst. Polar Res., Spec. Issue, 59, 79-95, 2006.

Hutjes, R. W. A., Vellinga, O. S., Gioli, B., and Miglietta, F.: Disaggregation of airborne flux measurements using footprint analysis, Agr. Forest Meteorol., 150, 966-983, 2010.

Initiative, N. S. S.: North Slope Science Initiative Landcover Mapping Summary Report, Electronic, available at: http://catalog.northslope.org/catalogs/ 6979-2013-nssi-landcover-for-north-slope-of-alaska (last access: 17 April 2014), 2013

Kinnard, C., Zdanowicz, C. M., Fisher, D. A., Isaksson, E., de Vernal, A., and Thompson, L. G.: Reconstructed changes in Arctic sea ice over the past 1450 years, Nature, 479, 509-U231, https://doi.org/10.1038/nature10581, 2011.

Kirby, S., Dobosy, R., Williamson, D., and Dumas, E.: An aircraftbased data analysis method for discerning individual fluxes in a heterogeneous agricultural landscape, Agr. Forest Meteorol., 148, 481-489, 2008

Kirschke, S., Bousquet, P., Ciais, P., Saunois, M., Canadell, J. G., Dlugokencky, E. J., Bergamaschi, P., Bergmann, D., Blake, D. R., Bruhwiler, L., Cameron-Smith, P., Castaldi, S., Chevallier, F., Feng, L., Fraser, A., Heimann, M., Hodson, E. L., Houweling, S., Josse, B., Fraser, P. J., Krummel, P. B., Lamarque, J.-F., Langenfelds, R. L., Le Quere, C., Naik, V., O'Doherty, S., Palmer, P. I., Pison, I., Plummer, D., Poulter, B., Prinn, R. G., Rigby, M., Ringeval, B., Santini, M., Schmidt, M., Shindell, D. T., Simpson, I. J., Spahni, R., Steele, L. P., Strode, S. A., Sudo, K., Szopa, S., van der Werf, G. R., Voulgarakis, A., van Weele, M., Weiss, R. F., Williams, J. E., and Zeng, G.: Three decades of global methane sources and sinks, Nat. Geosci., 6, 813-823, https://doi.org/10.1038/NGEO1955, 2013.

Kljun, N., Rotach, M., and Schmid, H.: A three-dimensional backward lagrangian footprint model for a wide range of boundary-layer stratifications, Bound.-Lay. Meteorol., 103, 205226, https://doi.org/10.1023/A:1014556300021, 2002.

Kljun, N., Calanca, P., Rotach, M., and Schmid, H.: A simple parameterisation for flux footprint predictions, Bound.-Lay. Meteorol., 112, 503-523, https://doi.org/10.1023/B:BOUN.0000030653.71031.96, 2004.

Kljun, N., Calanca, P., Rotach, M. W., and Schmid, H. P.: A simple two-dimensional parameterisation for Flux Footprint Prediction (FFP), Geosci. Model Dev., 8, 3695-3713, https://doi.org/10.5194/gmd-8-3695-2015, 2015.

Koven, C. D., Ringeval, B., Friedlingstein, P., Ciais, P., Cadule, P., Khvorostyanov, D., Krinner, G., and Tarnocai, C.: Permafrost carbon-climate feedbacks accelerate global warming, P. Natl. Acad. Sci. USA, 108, 14769-14774, https://doi.org/10.1073/pnas.1103910108, 2011.

LeMone, M. A., Grossman, R. L., Chen, F., Ikeda, K., and Yates, D.: Choosing the averaging interval for comparison of observed and modeled fluxes along aircraft transects over a heterogeneous surface, J. Hy- drometeorol., 4, 179-195, https://doi.org/10.1175/15257541(2003)4<179:CTAIFC>2.0.CO;2, 2003.

Mahrt, L.: Flux sampling errors for aircraft and towers, J. Atmos. Ocean. Tech., 15, 416-429, 1998.

Metzger, S., Junkermann, W., Mauder, M., Butterbach-Bahl, K., Trancón y Widemann, B., Neidl, F., Schäfer, K., Wieneke, S., Zheng, X. H., Schmid, H. P., and Foken, T.: Spatially explicit regionalization of airborne flux measurements using environmental response functions, Biogeosciences, 10, 2193-2217, https://doi.org/10.5194/bg-10-2193-2013, 2013.

Mudelsee, M.: Climate time series analysis, Springer, 2010.

Nguyen, H. and Walker, E. A.: A First Course In Fuzzy Logic, Chapman \& Hall/CRC, ISBN 0-8493-1659-6, 2000.

Oechel, W. C., Vourlitis, G. L., Brooks, S., Crawford, T. L., and Dumas, E.: Intercomparison among chamber, tower, and aircraft net $\mathrm{CO}_{2}$ and energy fluxes measured during the Arctic System Science Land-Atmosphere-Ice Interactions (ARCSS-LAII) Flux Study, J. Geophys. Res.-Atmos., 103, 28993-29003, 1998.

Oechel, W. C., Vourlitis, G. L., Verfaillie, J., Crawford, T., Brooks, S., Dumas, E., Hope, A., Stow, D., Boynton, B., Nosov, V., and Zulueta, R. A.: A scaling approach for quantifying the net $\mathrm{CO}_{2}$ flux of the Kuparuk River Basin, Alaska, Glob. Change Biol., 6, 160-173, 2000.

Olefeldt, D., Turetsky, M. R., Crill, P. M., and McGuire, A. D.: Environmental and physical controls on northern terrestrial methane emissions across permafrost zones, Glob. Change Biol., 19, 589-603, https://doi.org/10.1111/gcb.12071, 2013.

Paul, J., Lapson, L., and Anderson, J.: Ultrasensitive absorption spectroscopy with a high-finesse optical cavity and off-axis alignment, Appl. Optics, 40, 4904-4910, 2001.

Reagan, M. T., Moridis, G. J., Elliott, S. M., and Maltrud, M.: Contribution of oceanic gas hydrate dissociation to the formation of Arctic Ocean methane plumes, J. Geophys. Res.-Oceans, 116, C09014, https://doi.org/10.1029/2011JC007189, 2011.

Sayres, D. S., Moyer, E. J., Hanisco, T. F., Clair, J. M., Keutsch, F. N., O’Brien, A., Allen, N. T., Lapson, L., Demusz, J. N., Rivero, M., Martin, T., Greenberg, M., Tuozzolo, C., Engel, G. S., Kroll, J. H., Paul, J. B., and Anderson, J. G.: A new cavity based absorption instrument for detection of water isotopologues in the upper troposphere and lower stratosphere, Rev. Sci. Instrum., 80, https://doi.org/10.1063/1.3117349, 2009.

Sayres, D. S. and Dobosy, R.: Regional Methane and Carbon Dioxide Fluxes, https://doi.org/10.18739/A2JW84, 2013.

Schneider, J., Grosse, G., and Wagner, D.: Land cover classification of tundra environments in the Arctic Lena Delta based on Landsat 7 ETM+ data and its application for upscaling of methane emissions, Remote Sens. Environ., 113, 380-391, 2009.

Schuur, E. A. G., McGuire, A. D., Schaedel, C., Grosse, G., Harden, J. W., Hayes, D. J., Hugelius, G., Koven, C. D., Kuhry, P., Lawrence, D. M., Natali, S. M., Olefeldt, D., Romanovsky, V. E., Schaefer, K., Turetsky, M. R., Treat, C. C., and Vonk, J. E.: Climate change and the permafrost carbon feedback, Nature, 520, 171-179, https://doi.org/10.1038/nature14338, 2015.

Sepulveda-Jauregui, A., Walter Anthony, K. M., Martinez-Cruz, K., Greene, S., and Thalasso, F.: Methane and carbon dioxide emissions from 40 lakes along a north-south latitudinal transect in Alaska, Biogeosciences, 12, 3197-3223, https://doi.org/10.5194/bg-12-3197-2015, 2015. 
Shakhova, N., Semiletov, I., Leifer, I., Sergienko, V., Salyuk, A., Kosmach, D., Chernykh, D., Stubbs, C., Nicolsky, D., Tumskoy, V., and Gustafsson, O.: Ebullition and storm-induced methane release from the East Siberian Arctic Shelf, Nat. Geosci., 7, 6470, https://doi.org/10.1038/NGEO2007, 2014.

Sturtevant, C. S. and Oechel, W. C.: Spatial variation in landscapelevel $\mathrm{CO}_{2}$ and $\mathrm{CH}_{4}$ fluxes from arctic coastal tundra: influence from vegetation, wetness, and the thaw lake cycle, Glob. Change Biol., 19, 2853-2866, https://doi.org/10.1111/gcb.12247, 2013.

Sturtevant, C. S., Oechel, W. C., Zona, D., Kim, Y., and Emerson, C. E.: Soil moisture control over autumn season methane flux, Arctic Coastal Plain of Alaska, Biogeosciences, 9, 1423-1440, https://doi.org/10.5194/bg-9-1423-2012, 2012.

Tarnocai, C., Canadell, J. G., Schuur, E. A. G., Kuhry, P., Mazhitova, G., and Zimov, S.: Soil organic carbon pools in the northern circumpolar permafrost region, Global Biogeochem. Cy., 23, GB2023, https://doi.org/10.1029/2008GB003327, 2009.

Vellinga, O. S., Gioli, B., Elbers, J. A., Holtslag, A. A. M., Kabat, P., and Hutjes, R. W. A.: Regional carbon dioxide and energy fluxes from airborne observations using flight-path segmentation based on landscape characteristics, Biogeosciences, 7, 13071321, https://doi.org/10.5194/bg-7-1307-2010, 2010.

Vellinga, O. S., Dobosy, R. J., Dumas, E. J., Gioli, B., Elgers, J. A., and Hutjes, R. W. A.: Calibration and quality assurance of flux observations from a small research aircraft, J. Atmos. Ocean. Tech., 30, 161-181, 2013.

Walter, K. M., Edwards, M. E., Grosse, G., Zimov, S. A., and Chapin, F. S.: Thermokarst lakes as a source of atmospheric $\mathrm{CH}_{4}$ during the last deglaciation, Science, 318, 633-636, 2007a.

Walter, K. M., Smith, L. C., and Chapin, F. S.: Methane bubbling from northern lakes: present and future contributions to the global methane budget, Philos. T. Roy. Soc. A, 365, 1657-1676, 2007b.
Webb, E. K., Pearman, G. I., and Leuning, R.: Correction of Flux Measurements For Density Effects Due To Heat and Water-vapor Transfer, Q. J. Roy. Meteor. Soc., 106, 85-100, https://doi.org/10.1002/qj.49710644707, 1980.

Whiticar, M. and Schaefer, H.: Constraining past global tropospheric methane budgets with carbon and hydrogen isotope ratios in ice, Philos. T. Roy. Soc. A, 365, 1793-1828, https://doi.org/10.1098/rsta.2007.2048, 2007.

Witinski, M. F., Sayres, D. S., and Anderson, J. G.: High precision methane isotopologue ratio measurements at ambient mixing ratios using integrated cavity output spectroscopy, Applied Phys. B, 102, 375-380, https://doi.org/10.1007/s00340010-3957-2, 2011.

Wofsy, S. C.: HIAPER Pole-to-Pole Observations (HIPPO): finegrained, global-scale measurements of climatically important atmospheric gases and aerosols, Philos. T. Roy. Soc. A, 369, 2073 2086, https://doi.org/10.1098/rsta.2010.0313, 2011.

Yvon-Durocher, G., Allen, A. P., Bastviken, D., Conrad, R., Gudasz, C., St-Pierre, A., Thanh-Duc, N., and del Giorgio, P. A.: Methane fluxes show consistent temperature dependence across microbial to ecosystem scales, Nature, 507, 488-491, https://doi.org/10.1038/nature13164, 2014.

Zachos, J. C., Dickens, G. R., and Zeebe, R. E.: An early Cenozoic perspective on greenhouse warming and carbon-cycle dynamics, Nature, 451, 279-283, https://doi.org/10.1038/nature06588, 2008.

Zulueta, R. C., Oechel, W. C., Loescher, H. W., Lawrence, W. T., and Paw U, K. T.: Aircraft-derived regional scale $\mathrm{CO}_{2}$ fluxes from vegetated drained thaw-lake basins and interstitial tundra on the Arctic Coastal Plain of Alaska, Glob. Change Biol., 17, 2781-2802, https://doi.org/10.1111/j.13652486.2011.02433.x, 2011. 